\title{
Transport of stabilized iron nanoparticles in porous media: Effects of surface and solution chemistry and role of adsorption
}

\author{
Man Zhang ${ }^{\mathrm{a}, \mathrm{b}}$, Feng $\mathrm{He}^{\mathrm{c}, *}$, Dongye Zhao ${ }^{\mathrm{a}, *}$, Xiaodi Hao ${ }^{\mathrm{d}}$ \\ a Environmental Engineering Program, Department of Civil Engineering, Auburn University, \\ Auburn, Alabama 36849, USA \\ ${ }^{\mathrm{b}}$ Geosyntec Consultants, Inc., Minneapolis, Minnesota, USA \\ ${ }^{c}$ College of Biological and Environmental Engineering, Zhejiang University of Technology, \\ Hangzhou, China
}

${ }^{\mathrm{d}}$ The R \& D Center for Sustainable Environmental Biotechnology, Beijing University of Civil Engineering and Architecture, Beijing, China

*Corresponding authors:

Feng He (fenghe@zjut.edu.cn) +86 57188320387 (ph) +86 57188320884 (fax)

Dongye Zhao (zhaodon@auburn.edu) +1 3348446277 (ph) +1 3348446290 (fax) 


\begin{abstract}
Carboxymethyl cellulose (CMC) stabilized zero-valent iron (ZVI) (CMC-ZVI) nanoparticles have been extensively tested for remediation of soil and groundwater. This study investigated effects of iron oxide and aluminum oxide on retention and transport of CMC-ZVI nanoparticles, which have a mean hydrodynamic diameter of $155 \mathrm{~nm}$. Column breakthrough experiments showed that the metal oxides coatings on quartz sand greatly enhanced particle retention. A mechanistically sounder transport model was proposed by incorporating a Langmuir-type adsorption rate law into the classic convection-dispersion equation with the adsorption parameters derived from independent experiments. The model allows for a quantitative evaluation of the role of adsorption. While filtration is the primary mechanism for particle retention at lower pore flow velocities, adsorption becomes more significant at elevated velocities. The presence of 40-80 $\mathrm{mg}_{-} \mathrm{C} \mathrm{L}^{-1}$ of natural organic matter and high ionic strength (up to $200 \mathrm{mM} \mathrm{CaCl}_{2}$ ) had negligible effect on the breakthrough profiles of the nanoparticles. Starch, a neutral polysugar stabilizer, was also tested as a stabilizer. Starch-stabilized ZVI nanoparticles, with a mean hydrodynamic diameter of $303 \mathrm{~nm}$, displayed a higher particle retention than CMCZVI. The information and modeling approach can facilitate our understanding of fate and transport of stabilized ZVI nanoparticles under various geochemical conditions.
\end{abstract}

Keywords: Zero-valent iron; Nanoparticle; Transport modeling; Iron oxide coated sand; Aluminum oxide coated sand; Stabilized nanoparticles

\title{
1. Introduction
}


Zero valent iron (ZVI) nanoparticles have received considerable attention for in-situ remediation of contaminated soil and groundwater [1-3]. ZVI nanoparticles hold great potential for diverse remediation applications, from reductive dechlorination [4] to immobilization of metals and radionuclides $[5,6]$ in the subsurface. Based on a preliminary survey conducted by the U.S. Environmental Protection Agency (USEPA) [7], ZVI had been the most employed particulate materials used for in situ remediation.

ZVI nanoparticles are known to exhibit a core-shell structure, with an iron oxide $\left(\mathrm{Fe}_{3} \mathrm{O}_{4}\right.$ and $\left.\mathrm{Fe}_{2} \mathrm{O}_{3}\right)$ shell surrounding an $\mathrm{Fe}^{0}$ core [8]. Due to the van der Waals attractive force, dipole interactions and magnetic interactions, synthetic ZVI nanoparticles tend to aggregate rapidly into micro-scale, fractal, and chain-like clusters $[9,10]$. The particle aggregation not only causes loss in chemical reactivity, but also the soil deliverability, which is essential for in situ remediation [11]. Non-stabilized or aggregated ZVI nanoparticles are not deliverable in soil [12, 13].

To facilitate particle transport of nZVI nanoparticles in porous media, various surface modification techniques have been investigated using polyelectrolytes, polymers and surfactants as a coating agent or stabilizer $[12,14]$. The surface coatings introduce electrostatic and/or steric repulsions between nanoparticles and facilitate their transport in porous media. It was found that the type and concentration of the surface coatings greatly affect the particle aggregation, size and transport (He and Zhao 2007). In addition, environmental factors, such as flow conditions [15, 16], collector properties $[17,18]$, solution chemistry $[19,20]$ and nanoparticle surface properties $[8,21]$, can affect the stability and mobility of ZVI nanoparticles in porous media. For instances, the mobility of surface-modified ZVI was enhanced with increasing interstitial flow velocities due to reduced gravitational sedimentation and Brownian diffusion [15]. Raychoudhury et al. [17] observed an increased retention of ZVI nanoparticles with finer sands (from 775 to $150 \mu \mathrm{m}$ ) 
due to straining and/or wedging at the grain-to-grain contact point. Phenrat et al. (2009) reported the ZVI concentration has no effect on the transport behavior of poly(styrene sulfonate)-modified ZVI (PSS-ZVI), while Liang et al. [22] observed an increasing mobility of polyvinylpyrrolidonestabilized ZVI when the ZVI concentration was increased from 0.5 to $2 \mathrm{~g} \mathrm{~L}^{-1}$. The presence of naturally occurring organic molecules was reported to facilitate particle transport by enhancing electrosteric repulsion among nanoparticles [23-25]; however, organics may also serve as an inter-particle bridging agent between nanoparticles, resulting in significant aggregation and sedimentation of surface-modified ZVI nanoparticles [26].

Experimental investigations involving the transport of surface-modified ZVI nanoparticles are often conducted in glass beads or in cleaned quartz sand. There have been very limited studies with heterogeneous media $[18,27]$. However, common soil minerals, such as iron (hydr)oxides and aluminum (hydr)oxide, may strongly interact with the nanoparticles and the coating agents (which are often strong ligands), thereby strongly affecting the subsurface transport of nanoparticles [28-32]. Zhuang and Jin [33] studied transport of two bateriaophages in a goethite-coated sand column and observed that attachment of bateriophages was favored with the presence of goethite. Wang et al. [34] observed a similar effect of iron oxyhydroxide coatings on transport of hydroxyapatite nanoparticles. However, the transport of surfacemodified ZVI nanoparticles in metal oxides coated sand column has not been investigated.

Transport and deposition of nanoparticles in saturated porous media is typically interpreted using the classic convection-diffusion equation coupled with the filtration theory $[15,16,21,22$, 35, 36]. Adoring to the filtration theory, particles are retained in porous media through Brownian diffusion, interception, and gravitational sedimentation. Apparently, this theory does not distinguish adsorption (i.e., accumulation of particles on the collector surface through direct 
particle-collector interactions) from other filtration removal mechanisms. Consequently, the role of nanoparticle adsorption on the collector grains has not been addressed. Prior work [37] revealed that CMC-stabilized ZVI nanoparticles can be strongly adsorbed to a sandy soil. Yet, quantitative information remains missing on how adsorption affects the particle deposition and transport in porous media.

The overall goal of this study was to investigate the effects of surface metal oxides and solution chemistry on transport of CMC-stabilized ZVI nanoparticles and determine the role of particle adsorption. The specific objectives were to: 1) examine the breakthrough behaviors of CMC-stabilized ZVI nanoparticles through quartz sand, iron oxide-coated sand (IOCS), and aluminum oxide-coated sand (AOCS); 2) elucidate the effects of surface metal oxide coatings on particle transport; 3) simulate the particle transport using a modified mathematical model that quantifies contributions of adsorption and filtration to the overall particle deposition; and 4) determine the effects of particle concentration, ionic strength, natural organic matter (NOM) and polymer stabilizers on the transport of ZVI nanoparticles.

\section{Material and Methods}

\subsection{Chemicals}

Chemicals used are presented in Section 1 of the Supplementary Material (SM). Dissolved NOM was obtained by extracting a potting soil (HYPONEX®, OH, USA) following the method described in [37]. In brief, $63 \mathrm{~mL}$ of deionized (DI) water was mixed with $36 \mathrm{~g}$ of the potting soil for 3 days. Upon centrifugation, the supernatant was filtered through a $0.45 \mu \mathrm{m}$ cellulose membrane and then the filtrate was stored in a refrigerator at $4^{\circ} \mathrm{C}$. The concentration of dissolved

NOM was determined to be $860 \mathrm{mgL}^{-1}$ as total organic carbon (TOC) using a ultravioletpersulfate TOC analyzer (Tekmar-Dohrmann Phoenix 8000, Mason, OH). Bromide in the tracer 
tests was measured using an Ion Chromatograph (DX-120, Dionex, Sunnyvale, CA) with an AS14 analytical column.

\subsection{Preparation of stabilized ZVI nanoparticles}

CMC- or starch-stabilized ZVI nanoparticles were prepared following the particle stabilization technique $[3,12]$. In each batch, a nanoparticle suspension was first prepared at 1.0 $\mathrm{g} \mathrm{L}^{-1}$ as $\mathrm{Fe}$ in the presence of $0.8 \% \mathrm{CMC}$ or starch, the stock suspension was immediately diluted to $0.2 \mathrm{~g} \mathrm{~L}^{-1}$ using deoxygenated DI water, and then used freshly in the subsequent tests. The hydrodynamic particles size was determined through the dynamic light scattering (DLS) measurements and the $\zeta$-potential of the nanoparticles was obtained using a Zetasizer Nano analyzer (Malvern, Southborough, MA). The concentration of the ZVI nanoparticles was determined as follows: first, completely dissolve the nanoparticles using concentrated $\mathrm{HCl}$ at a HCl-to-ZVI suspension volume ratio of 1:4 and then analyzed for total Fe using an inductively coupled plasma atomic emission spectroscopy (ICP-AES) (Liberty-Series II, Varian, Palo Alto, CA).

\subsection{Preparation of Porous Media}

Quartz sand (Accusand 40/60) (0.21 to $0.42 \mathrm{~mm}$ ) was purchased from Unimin Corporation (Le Sueur, MN, USA). Prior to use, the sand grains were cleansed as described in [15] and Section 2 of SM. IOCS was prepared based on a modified precipitation method [38, 39]. In brief, $150 \mathrm{~g}$ of the washed quartz sand was first mixed with $80 \mathrm{~mL}$ of $2.1 \mathrm{M} \mathrm{Fe}\left(\mathrm{NO}_{3}\right)_{3}$. The $\mathrm{pH}$ of the slurry was raised to 12 by drop-wise addition of a $10 \mathrm{M} \mathrm{NaOH}$ solution and then oven-dried at $110^{\circ} \mathrm{C}$ for 14 hours. Upon cooling, the resultant material was repeatedly washed with DI water, and oven-dried at $110^{\circ} \mathrm{C}$ for 3 hours, and then air-dried for 21 hours at room temperature; the wash-dry process was repeated until no iron leached off from the sand. AOCS was prepared 
based on the method by Kuan et al. [40]. Briefly, $150 \mathrm{~g}$ of the quartz sand was soaked with 100 $\mathrm{mL}$ of a $1 \mathrm{M}$ of $\mathrm{AlCl}_{3}$ solution. Then, a $4.0 \mathrm{M} \mathrm{NaOH}$ solution was added drop-wise to raise the $\mathrm{pH}$ to 11 . After mixing for $15 \mathrm{~min}$, the suspension was oven-dried at $70^{\circ} \mathrm{C}$ for 2 days. The sand was then repeatedly washed with DI water followed by oven-drying at $70^{\circ} \mathrm{C}$ for $3 \mathrm{~h}$ until the rinse-off was free of aluminum. There was no appreciable change in the size of the sand grains upon the coatings per standard sieve measurement. The total amount of iron and alumina loaded on the sand was determined to be 4.14 and $3.6 \mathrm{mg} \mathrm{g}^{-1}$, respectively, per EPA Method 3050b using the ICP-AES.

\subsection{Column transport experiments}

Column breakthrough tests of stabilized ZVI nanoparticles were carried out to probe the transport behaviors of the nanoparticles through three model media (pristine sand, IOCS and AOCS). Section 3 of SM provides the experimental details.

\subsection{Adsorption of stabilized ZVI nanoparticles on porous media}

Batch adsorption kinetic and isotherm tests were conducted in $43 \mathrm{~mL}$ borosilicate glass vials to investigate the adsorption of stabilized ZVI nanoparticles on the quartz sand, IOCS and AOCS. Section 4 of SM presents the experimental details.

\subsection{Transport model distinguishing adsorption from filtration}

A modified one-dimensional convection-dispersion model was employed to simulate transport of stabilized ZVI nanoparticles in the three media. The model was based on the commonly used governing equation [41],

$$
\frac{\partial \mathrm{C}}{\partial \mathrm{t}}+\frac{\rho_{\mathrm{b}}}{\theta_{\mathrm{w}}} \frac{\partial \mathrm{S}}{\partial \mathrm{t}}=\mathrm{D}_{\mathrm{H}} \frac{\partial^{2} \mathrm{C}}{\partial \mathrm{x}^{2}}-\mathrm{v}_{\mathrm{p}} \frac{\partial \mathrm{C}}{\partial \mathrm{x}}
$$

where $\mathrm{x}$ is distance along the sand bed $(\mathrm{cm}), \mathrm{t}$ is time (s), C is concentration of ZVI nanoparticles

$\left(\mathrm{mg} \mathrm{L}^{-1}\right)$, $\mathrm{S}$ is concentration of adsorbed ZVI $\left(\mathrm{mg} \mathrm{g}^{-1}\right), \mathrm{D}_{\mathrm{H}}$ is hydrodynamic dispersion coefficient 
$\left(\mathrm{cm}^{2} \mathrm{~s}^{-1}\right), \mathrm{v}_{\mathrm{p}}$ is pore flow velocity $\left(\mathrm{cm} \mathrm{s}^{-1}\right), \rho_{\mathrm{b}}$ is bulk density of the porous media $\left(\mathrm{g} \mathrm{L}^{-1}\right)$, and $\theta_{\mathrm{w}}$ is water content of the media (dimensionless), which is equal to the porosity under saturated conditions.

Conventionally, the overall particle deposition is lumped to the filtration effects without distinguishing the specific role of adsorption. Accordingly, a lumped pseudo first-order rate law is often invoked to describe the deposition kinetics. In this work, we propose a mechanistically sounder rate equation by breaking the overall deposition rate into an adsorption term and a filtration term, i.e.,

$$
\frac{\rho_{\mathrm{b}}}{\theta_{\mathrm{w}}} \frac{\partial \mathrm{S}}{\partial \mathrm{t}}=\mathrm{k}_{\mathrm{ads}} \psi \mathrm{C}+\mathrm{k}_{\mathrm{flt}} \mathrm{C}-\frac{\rho_{\mathrm{b}}}{\theta_{\mathrm{w}}} \mathrm{k}_{\mathrm{det}} \mathrm{S}
$$

where $\mathrm{k}_{\mathrm{ads}}$ is the adsorption rate constant $\left(\mathrm{s}^{-1}\right), \mathrm{k}_{\mathrm{flt}}$ is the first-order filtration rate constant $\left(\mathrm{s}^{-1}\right)$, $\mathrm{k}_{\mathrm{det}}$ is the first-order detachment rate constant $\left(\mathrm{s}^{-1}\right)$, and $\Psi$ is a blocking function to describe the available adsorption sites on the collectors, which is described by [41]:

$$
\psi=\frac{\mathrm{S}_{\max }-\mathrm{S}}{\mathrm{S}_{\max }}
$$

where $S_{\max }$ is the maximum adsorption capacity of the nanoparticles $\left(\mathrm{mg}^{-1}\right)$, which is determined from the adsorption isotherm. Adsorption of CMC-stabilized nanoparticles to metal oxides can occur, for example, through monodentate complexation and hydrogen bonding [12] between the stabilizers and the Lewis acids (Fe or $\mathrm{Al})$.

The adsorption rate can be conveniently determined through batch adsorption kinetic tests in completely stirred batch reactors, where the filtration mechanisms are negligible. In this work, $\mathrm{k}_{\mathrm{ads}}$ was determined by fitting Eq. (4) to the batch adsorption rate data:

$$
\mathrm{M} \frac{\partial \mathrm{S}}{\partial \mathrm{t}}=\mathrm{k}_{\mathrm{ads}} \frac{\mathrm{S}_{\max }-\mathrm{S}}{\mathrm{S}_{\max }} \mathrm{CV}
$$


where $\mathrm{M}(\mathrm{g})$ is the total mass of an adsorbent, and $\mathrm{V}(\mathrm{L})$ is the volume of the nanoparticles suspension.

Column elution tests (Section 3.1) indicated that the deposition of the ZVI nanoparticles was virtually irreversible. Consequently, Eq. (2) is reduced to

$$
\frac{\rho_{\mathrm{b}}}{\theta_{\mathrm{w}}} \frac{\partial \mathrm{S}}{\partial \mathrm{t}}=\mathrm{k}_{\mathrm{ads}} \psi \mathrm{C}+\mathrm{k}_{\mathrm{flt}} \mathrm{C}
$$

The revised rate equation allows for quantitative evaluation of the role of adsorption in the overall transport of the nanoparticles. Under the experimental initial and boundary conditions, the Hydrus-1D code was used to solve the governing transport equation (Eq. 1) and to facilitate fitting of the model to the experimental breakthrough data with $\mathrm{k}_{\mathrm{flt}}$ being the sole fitting parameter.

\section{Results and Discussion}

\subsection{Transport of CMC-stabilized ZVI nanoparticles}

Figure 1 presents the breakthrough curves of the tracer $\left(\mathrm{Br}^{-}\right)$and CMC-ZVI nanoparticles through quartz sand, IOCS and AOCS. For all the media, the breakthrough of the tracer started nearly simultaneously at $\sim 1$ pore volume (PV) and rose to $100 \%$ breakthrough at $\sim 1.5 \mathrm{PV}$. The fairly symmetrical breakthrough profiles of the tracer suggested that the effect of flow nonidealities (i.e., channeling and/or stagnant zone in the media beds) was negligible and no physical non-equilibrium was involved [41]. The nearly identical breakthrough curves of the tracer for the three different media indicate that the coating of metal oxides had little effects on hydrodynamic characteristics and dispersive properties of the porous media.

The stabilized nanoparticles displayed superior mobility. In all cases, the nanoparticle breakthrough started at $\sim 1 \mathrm{PV}$, and then rose sharply to a steady full breakthrough concentration plateau at $\sim 1.5 \mathrm{PV}$. The sharp breakthrough profiles for the tracer and nanoparticles nearly 
coincided, suggesting little dispersion effect. However, the porous media showed different degrees of nanoparticle removal, with a full breakthrough $C / C_{0}$ of 0.90 for the plain sand, 0.76 for IOCS and 0.76 for AOCS.

The elution profiles for all media appeared nearly symmetrical to the breakthrough curves. The sharp decrease of ZVI concentration without any significant tailing indicates that the release of the nanoparticles from the sand grains was negligible (i.e., $\mathrm{k}_{\mathrm{det}} \approx$ zero) [41]. Such irreversible deposition is of great practical significance as it is often desired that the nanoparticles delivered in the subsurface will remain in a confined domain.

Based on TEM measurements, the mean particle size of the nanoparticles is $11.2 \pm 7.9 \mathrm{~nm}$ (standard deviation), which translates into a specific surface area of $68 \mathrm{~m}^{2} \mathrm{~g}^{-1}$. The hydrodynamic diameter of the nanoparticles was $155 \mathrm{~nm}$. The nanoparticle-to-sand size ratio is $3.8 \times 10^{-4}$, which is one order of magnitude lower than the threshold value of 0.005 for straining [42]. Figure 2 presents the spatial distribution of the nanoparticles in the sand bed following the column runs (breakthrough and elution). Non-parametric Mann-Kendall analysis was conducted for the retained mass of ZVI in the sand columns, which indicated no trend over the travel distance, confirming the absence of straining effect. Raychoudhury et al. [17] evaluated breakthrough patterns of CMC-stabilized ZVI through differently sized sand (150 to $775 \mu \mathrm{m})$ and observed higher ZVI retention near the inlet for finer sand. The authors attributed the higher retention to formation of large aggregates over time. However, in our study, the hydrodynamic size of the nanoparticles barely changed within two hours of each experiment even in the presence of 200 $\mathrm{mM} \mathrm{CaCl}_{2}$ (Figure 3). A notable difference is that the pore velocity in this work $\left(0.0353 \mathrm{~cm} \mathrm{~s}^{-1}\right)$ was $~ 1.5$ times higher, which would increase the shear and drag forces acting on ZVI nanoparticles near the sand surface [43]. 
The higher retention of CMC-ZVI nanoparticles on IOCS and AOCS is attributed to the presence of positively-charged or weakly negatively-charged metal oxides coatings, which provide electrostatically favorable conditions for binding with the negatively charged nanoparticles. CMC-ZVI nanoparticles carry a very negative $\zeta$-potential of $-160 \mathrm{mV}$ under the experimental conditions due to the $\mathrm{CMC}$ coating. The $\mathrm{pH}$ at point of zero charge $\left(\mathrm{pH}_{\mathrm{pzc}}\right)$ was measured to be 7.53 for IOCS and 8.65 for AOCS, which are consistent with reported values [40, 44]; in contrast, $\mathrm{pH}_{\mathrm{pzc}}$ for the neat quartz sand was $\sim 2$ [45]. Therefore, under the experimental $\mathrm{pH}$ ( 7.9 for plain sand, $\sim 7.9$ for ICOCS, and 8.2 for AOCS), IOCS is only partially deprotonated, and AOCS largely positively charged, while the plain sand is completely deprotonated.

Besides, CMC serves as a bridging ligand between the nanoparticles and the metal oxide coated media. On one hand, CMC is firmly anchored on the nanoparticles primarily through monodentate complexation between the carboxylate groups and iron oxide shell [12]; on the other hand, $\mathrm{CMC}$ can interact with the metal ions ( $\mathrm{Al}$ and $\mathrm{Fe})$ on the sand surface via strong Lewis acid-base interaction. As a result, more nanoparticles were deposited on the metal oxide coated media.

The amount of iron oxide and aluminum oxide on the sand $0.074 \mathrm{mmol} \mathrm{g}^{-1}$ and $0.13 \mathrm{mmol} \mathrm{g}$ ${ }^{1}$, respectively. The fact that the deposition of CMC-ZVI on IOCS and AOCS was almost the same indicates that iron oxide is more effective than aluminum oxide to retain CMC-ZVI nanoparticles. This is in accordance with the fact that iron is a softer Lewis acid and interacts more strongly with carboxylate groups of CMC than aluminum [46].

To quantify the relative contributions of adsorption and filtration to the deposition of CMCZVI nanoparticles, batch adsorption tests of CMC-ZVI nanoparticles on sand-based media were performed, where adsorption was the single most important mechanism for particle removal. 
Figures $4 \mathrm{a}$ and $4 \mathrm{~b}$ show the adsorption isotherms and kinetics, respectively. The results confirm that IOCS and AOSC offer much greater adsorption capacity than the plain sand.

The classic Langmuir model was employed to interpret the isotherm data,

$$
q=\frac{b Q C}{1+b C}
$$

where $\mathrm{q}$ is the equilibrium uptake of the nanoparticles $\left(\mathrm{mg} \mathrm{g}^{-1}\right), \mathrm{C}$ is the equilibrium concentration of the nanoparticles in the aqueous phase $\left(\mathrm{mg} \mathrm{L}^{-1}\right), \mathrm{Q}$ is the Langmuir capacity $(\mathrm{mg}$ $\left.\mathrm{g}^{-1}\right)$, and $\mathrm{b}$ is the Langmuir affinity constant $\left(\mathrm{L} \mathrm{mg}^{-1}\right)$. Table 1 lists best-fitted model parameters.

The kinetic model (Eq. 4) was used to interpret the kinetic data, and the best-fit gave the rate constant (Table 1). The maximum uptake $S_{\max }$ was determined as the equilibrium uptake of nanoparticles from the isotherm data at the nanoparticle concentration corresponding to the steady-state effluent concentration in the column breakthrough tests. Tripling or quadrupling the sand-to-liquid ratio had little effect on the sorption rate constant $\left(0.0096 \pm 0.0002 \mathrm{~h}^{-1}\right)($ standard deviation). Thus, the mean $\mathrm{k}_{\mathrm{ads}}$ was used in Eq. (5) for simulating the column breakthrough curves. The best curve fitting gave the filtration rate constant $\left(\mathrm{k}_{\mathrm{fil}}\right)($ Table 1$)$.

It is noteworthy that the filtration rate constant is approximately two orders of magnitude greater than the adsorption rate constant for the three media under the experimental conditions. It is evident from Eq. (5) that filtration is the primary mechanism for the particle deposition, and adsorption plays a relatively minor role in all cases. When the three media are compared, the metal oxide coatings increased $\mathrm{k}_{\mathrm{fil}}$ by a factor of $\sim 2.2$ compared to the plain sand, and $\mathrm{k}_{\mathrm{ads}}$ by 1.6 1.8, indicating the metal oxides increased both adsorptive and filtration removal of the nanoparticles.

However, the role of adsorption becomes more significant at elevated pore flow velocity. For example, when the pore velocity was doubled to $0.0706 \mathrm{~cm} \mathrm{~s}^{-1}$ in the plain sand column, $\mathrm{k}_{\text {fil }}$ was 
reduced to $5.63 \times 10^{-5} \mathrm{~s}^{-1}$, i.e., the role of filtration was lowered by $74 \%$. The tangential flow around a spherical collector would project a shadow zone on the collector surface down gradient of a deposited particle, which is not accessible for subsequent particles. Increasing the flow velocity would result in a larger shadow zone, yielding a reduced deposition during colloid filtration [47].

\subsection{Effect of CMC-ZVI nanoparticle concentration}

Figure 5 shows that the normalized effluent particle concentration $\left(\mathrm{C} / \mathrm{C}_{0}\right)$ increased when the influent ZVI concentration increased from 0.05 to $0.8 \mathrm{~g} \mathrm{~L}^{-1}$ in the sand column. At $7.5 \mathrm{PV}$, the $\mathrm{C} / \mathrm{C}_{0}$ values were $0.97,0.89$ and 0.83 in response to influent concentrations of $0.8,0.2$ and $0.05 \mathrm{~g}$ $\mathrm{L}^{-1}$, respectively. This seemingly counterintuitive effect can be attributed to the "blocking" effect due to a limited surface capacity of porous media for particle deposition [48-50]. The deposited nanoparticles would occupy the available sites and block subsequent deposition of nanoparticles due to electrostatic repulsion. A higher concentration of ZVI would result in more rapid surface coverage of the nanoparticles on the sands and lead to greater "blocking" effect. Furthermore, the full-breakthrough $\mathrm{C} / \mathrm{C}_{0}$ value exhibited a rising trend as of the influent nanoparticle concentration was elevated, confirming a declined deposition rate due to elevated blocking. Due to the stabilizer effect, multilayer uptake of nanoparticles is unfavorable. In addition, the higher viscosity of the polymer solutions at elevated ZVI concentrations can exert stronger flow drag forces that reduce the orthokinetic aggregation and differential sedimentation, as predicted by the Smoluchowski formula and Stoke's law [51].

However, when particle aggregation occurs in the solution, the transport behavior of ZVI nanoparticles at different concentrations would vary. Phenrat et al. [52] reported that due to particle agglomeration, the PSS-ZVI concentration (1-6 $\left.\mathrm{g} \mathrm{L}^{-1}\right)$ showed no effect on the particle 
deposition efficiency. Raychoudhury et al. [53] reported that due to insufficient CMC concentration, CMC-ZVI particles increasingly aggregated as ZVI concentration was increased from 0.07 to $0.725 \mathrm{mg} \mathrm{L}^{-1}$. As a result, the breakthrough $\mathrm{C} / \mathrm{C}_{0}$ value decreased from 0.75 to 0.61 .

\subsection{Effect of Ionic strength}

The CMC-ZVI nanoparticles remained stable in the presence of high concentrations of calcium cation (up to $200 \mathrm{mM}$ ). With the addition of 40,100 and $200 \mathrm{mM} \mathrm{CaCl}_{2}$, the zeta potential of CMC-ZVI was suppressed from $-160 \mathrm{mV}$ to $-24.7,-19.2$ and $-16.3 \mathrm{mV}$, respectively, due to compression of the electrical double layer and charge neutralization; accordingly, the hydrodynamic particle size decreased slightly from $155 \mathrm{~nm}$ to $130.5,127.5$ and $125.3 \mathrm{~nm}$, which could be due to the formation of calcium-dicarboxylate cross-links [54, 55]. Calcium ions can bridge carboxyl groups and decrease the swelling of CMC molecules, which results in shrinkage of the hydrated CMC macromolecules on the nanoparticle surface [54]. However, no aggregation was evident in the presence of $\mathrm{CaCl}_{2}$ (Figure 3), which confirms the superior particle stabilizing power of $\mathrm{CMC}$ that prevents particle aggregation through concurrent electrostatic and steric repulsions.

Figure 6 reveals that the breakthrough curves with 0 and $200 \mathrm{mM} \mathrm{CaCl}{ }_{2}$ nearly coincided, indicating negligible effect of the electrolyte on the particle transport. This result is consistent with findings where sterically stabilized particles were tested [56, 57].

\subsection{Effect of natural organic matter}

Figure 7 presents the breakthrough curves of CMC-ZVI nanoparticles through the plain sand column at various concentrations of NOM measured as TOC. Fatisson et al. [58] reported that 2

$\mathrm{mg} \mathrm{L}^{-1}$ (as TOC) Suwannee River fulvic acid had no appreciable effect on the deposition of CMC-ZVI nanoparticles on silica. In our study, when the NOM concentration increased from 0 
to $40 \mathrm{mg} \mathrm{L}^{-1}, \mathrm{C} / \mathrm{C}_{0}$ after $7.5 \mathrm{PV}$ decreased slightly from 0.89 to 0.86 . However, when the NOM concentration was further increased to $80 \mathrm{mg} \mathrm{L}^{-1}$, the $\mathrm{C} / \mathrm{C}_{0}$ value rose to 0.93 . It has been reported that NOM is capable of enhancing transport of colloidal hematite [59], titanium dioxide [60], a type of aggregated ZVI [25], and latex particles [24, 61]. In these cases, negatively charged NOM could modify the surface property of colloids or porous media upon adsorption on their surfaces, which increase both electrostatic and steric repulsions between colloids and particle collectors.

In this study, the addition of 40 and $80 \mathrm{mg} \mathrm{L}^{-1} \mathrm{NOM}$ slightly suppressed the zeta potential from -160 to -150 and $-151 \mathrm{mV}$, respectively, which can be attributed to partial replacement of CMC on the nanoparticle surface with NOM. The $\zeta$-potential was nearly the same when NOM concentration increased from 40 to $80 \mathrm{mg} \mathrm{C} \mathrm{L}^{-1}$. However, the breakthrough plateau $\left(\mathrm{C} \mathrm{C}_{0}\right)$ increased from 0.86 to 0.93 . This can be attributed to the competition between NOM and CMCZVI for the attachment sites on the collectors. The $\zeta$-potential of NOM macromolecules was measured to be $-20.1 \mathrm{mV}$ at $\mathrm{pH} \sim 8$. The competitive adsorption of NOM on sand could occur via retention in the secondary energy minimum wells. In general, particle deposition in a deep secondary energy minimum well controls transport of colloids and bacteria in porous media under unfavorable electrostatic conditions [43, 62-64]. Based on the DLVO theory, the sum of van der Waals and electrostatic interactions between particles will result in primary or secondary minimum sections where the attractive force dominates. Under unfavorable electrostatic conditions, colloids can be captured onto the collector surface in the secondary minimum domain provided the secondary minimum is deep enough $[65,66]$. With smaller molecular size and lower surface charge density, NOM molecules are likely more competitive than CMC-ZVI for secondary energy minimum deposition. 


\subsection{Effect of stabilizer type on transport of ZVI nanoparticles}

The effects of two types of polysaccharide stabilizers, i.e., starch and CMC, were investigated. Starch is a neutral poly-sugar consisting of $\alpha$-D-glucose monomers, with a molecular formula of $\left[\mathrm{C}_{6} \mathrm{H}_{10} \mathrm{O}_{5}\right]_{n}$. Starch can be attached on the surface of ZVI nanoparticles through hydrogen bonding between the hydroxyl groups of glucose units and the iron oxide shell. The starch coating stabilizes the nanoparticles through steric hindrance with a rather neutral $\zeta$ potential of $-4 \mathrm{mV}$. CMC is a derivative from cellulose made of $\beta$-D-glucoses by substituting part of hydroxyl groups with carboxymethyl groups. As the carboxylate groups undergo complete dissociation under typical groundwater $\mathrm{pH}$, the $\mathrm{CMC}$ coating induces a very negative potential $(\zeta=-160 \mathrm{mV})$, thereby stabilizing the nanoparticles through concurrent electrostatic repulsion and steric hindrance. The hydrodynamic diameter of CMC-ZVI was measured to be $155 \mathrm{~nm}$, which is about half of that for starch-ZVI (303 nm).

For both types of nanoparticles, the hydrodynamic particle size and $\zeta$-potential remained nearly constant during the 2 hours of monitoring (Figure 4) and no significant aggregation or sedimentation was observed, indicating that both stabilizers were effective in preventing aggregation of the nanoparticles.

Figure 8 compares the breakthrough and the subsequent elution curves of CMC- and starchstabilized ZVI nanoparticles through the plain sand columns. While both types of the nanoparticles were transportable through the medium, more starch-ZVI was retained in the sand bed than $\mathrm{CMC}-\mathrm{ZVI}$, with a full breakthrough $\mathrm{C} / \mathrm{C}_{0}$ of 0.83 for starch-ZVI and 0.90 for $\mathrm{CMC}$ ZVI. Like CMC-ZVI, a sharp elution curve was obtained for starch-stabilized ZVI nanoparticles, suggesting that the deposition of the nanoparticles was nearly irreversible. 
The coating of the stabilizers can shield the nanoparticles from directly interacting with the sand surface through steric and/or electrosteric repulsion, thereby improving the particle mobility. Tong et al. [67] reported that the extracellular polymers on the bacteria surface could decrease the number of collisions between bacteria and collectors via steric repulsion. Between starch and CMC, the greater retention of starch-ZVI is attributed to: 1) the larger particle size of starch-ZVI, and 2) the more favorable interacting conditions between the nearly neutral starchZVI and the negative sand surfaces. However, the higher viscosity of the starch solution is expected to facilitate particle mobility.

\section{Conclusions}

This study investigated the effects of surface metal oxides on the transport behaviors of CMC-stabilized ZVI nanoparticles under various solution conditions, and evaluated the role of particle adsorption by means of a modified transport modeling approach. As metal oxides are ubiquitous in soil, the results can guide in-situ application of the nanoparticles as a potentially cost-effective remediation technique [68]. Both iron oxide and aluminum oxide enhanced ZVI deposition on the sand media due to enhanced particle-collector interactions and diminished electrostatic repulsion. This work presents a modified modeling approach by distinguishing a specific adsorption rate law from the conventional lumped first-order filtration kinetic equation, which allows for a quantitative appraisal of adsorptive deposition as opposed to overall filtration removal of nanoparticles or colloids at large. Adsorption becomes more important in the deposition and transport of CMC-stabilized ZVI nanoparticles at higher flow velocities. A lower retention of CMC-stabilized ZVI nanoparticles was observed when the influent particle

concentration was increased from 0.05 to $0.8 \mathrm{~g} \mathrm{~L}^{-1}$ due to the blocking effect. The presence of 40-80 mg C L $\mathrm{L}^{-1}$ of NOM only modestly affected the transport of the nanoparticles, and the 
presence of $200 \mathrm{mM} \mathrm{CaCl}$ did not significantly alter the transport behavior. While $\mathrm{CMC}$ is a much stronger stabilizer than starch, the coating of the neutral polysugar (starch) resulted in more retention of starch-ZVI, which can be useful when more particle deposition is desired, e.g., when a ZVI reactive zone is to be established.

\section{Acknowledgements}

Partial financial supports from the National Natural Science Foundation of China (41230638 and 51308312) and a USDA-AAES Hatch Award are gratefully acknowledged.

\section{References}

[1] K.D. Grieger, A. Fjordbøge, N.B. Hartmann, E. Eriksson, P.L. Bjerg, A. Baun, Environmental benefits and risks of zero-valent iron nanoparticles (nZVI) for in situ remediation: risk mitigation or trade-off?, J. Contam. Hydrol., 118 (2010) 165-183.

[2] R. Crane, T. Scott, Nanoscale zero-valent iron: future prospects for an emerging water treatment technology, J. Hazard. Mater., 211 (2012) 112-125.

[3] F. He, D.Y. Zhao, Preparation and characterization of a new class of starch-stabilized bimetallic nanoparticles for degradation of chlorinated hydrocarbons in water, Environ. Sci. Technol., 39 (2005) 3314-3320.

[4] C.B. Wang, W.X. Zhang, Synthesizing nanoscale iron particles for rapid and complete dechlorination of TCE and PCBs, Environ. Sci. Technol., 31 (1997) 2154-2156.

[5] M. Hashim, S. Mukhopadhyay, J.N. Sahu, B. Sengupta, Remediation technologies for heavy metal contaminated groundwater, Journal of environmental management, 92 (2011) 2355-2388. [6] P.E. Dresel, M.J. Truex, K. Cantrell, Remediation of deep vadose zone radionuclide and metal contamination: Status and Issues, Pacific Northwest National Laboratory, Richland, Washington, 2008. 
[7] OSWER, Selected sites using or testing nanoparticles for remediation. http://epa.gov/tio/download/remed/nano-site-list.pdf, in, 2011.

[8] Y.H. Lin, H.H. Tseng, M.Y. Wey, M.D. Lin, Characteristics of two types of stabilized nano zero-valent iron and transport in porous media, Sci. Total Environ., 408 (2010) 2260-2267.

[9] B.L. Cushing, V.L. Kolesnichenko, C.J. O'Connor, Recent advances in the liquid-phase syntheses of inorganic nanoparticles, Chem. Rev., 104 (2004) 3893-3946.

[10] T. Phenrat, N. Saleh, K. Sirk, R.D. Tilton, G.V. Lowry, Aggregation and sedimentation of aqueous nanoscale zerovalent iron dispersions, Environ. Sci. Technol., 41 (2007) 284-290.

[11] Y.S. Hong, R.J. Honda, N.V. Myung, S.L. Walker, Transport of iron-based nanoparticles: role of magnetic properties, Environ. Sci. Technol., 43 (2009) 8834-8839.

[12] F. He, D.Y. Zhao, J.C. Liu, C.B. Roberts, Stabilization of Fe-Pd nanoparticles with sodium carboxymethyl cellulose for enhanced transport and dechlorination of trichloroethylene in soil and groundwater, Ind. Eng. Chem. Res., 46 (2007) 29-34.

[13] S.R. Kanel, R.R. Goswami, T.P. Clement, M.O. Barnett, D. Zhao, Two dimensional transport characteristics of surface stabilized zero-valent iron nanoparticles in porous media, Environ. Sci. Technol., 42 (2008) 896-900.

[14] S.R. Kanel, D. Nepal, B. Manning, H. Choi, Transport of surface-modified iron nanoparticle in porous media and application to arsenic (III) remediation, Journal of Nanoparticle Research, 9 (2007) 725-735.

[15] F. He, M. Zhang, T.W. Qian, D.Y. Zhao, Transport of carboxymethyl cellulose stabilized iron nanoparticles in porous media: Column experiments and modeling, J. Colloid Interface Sci., 334 (2009) 96-102. 
[16] T. Phenrat, H.-J. Kim, F. Fagerlund, T. Illangasekare, G.V. Lowry, Empirical correlations to estimate agglomerate size and deposition during injection of a polyelectrolyte-modified Fe0 nanoparticle at high particle concentration in saturated sand, J. Contam. Hydrol., 118 (2010) 152164.

[17] T. Raychoudhury, N. Tufenkji, S. Ghoshal, Straining of polyelectrolyte-stabilized nanoscale zero valent iron particles during transport through granular porous media, Water Res., 50 (2014) 80-89.

[18] M. Basnet, C.D. Tommaso, S. Ghoshal, N. Tufenkji, Reduced transport potential of a palladium-doped zero valent iron nanoparticle in a water saturated loamy sand, Water Res., 5 (2014) 354-363.

[19] S. Laumann, V. Micić, T. Hofmann, Mobility enhancement of nanoscale zero-valent iron in carbonate porous media through co-injection of polyelectrolytes, Water Res., 50 (2014) 70-79. [20] N. Saleh, H.J. Kim, T. Phenrat, K. Matyjaszewski, R.D. Tilton, G.V. Lowry, Ionic strength and composition affect the mobility of surface-modified $\mathrm{Fe}^{0}$ nanoparticles in water-saturated sand columns, Environ. Sci. Technol., 42 (2008) 3349-3355.

[21] T. Raychoudhury, G. Naja, S. Ghoshal, Assessment of transport of two polyelectrolytestabilized zero-valent iron nanoparticles in porous media, J. Contam. Hydrol., 118 (2010) 143151.

[22] B. Liang, Y. Xie, Z. Fang, E. Tsang, Assessment of the transport of polyvinylpyrrolidonestabilised zero-valent iron nanoparticles in a silica sand medium, Journal of Nanoparticle Research, 16 (2014) 1-11. 
[23] S.E. Mylon, K.L. Chen, M. Elimelech, Influence of natural organic matter and ionic composition on the kinetics and structure of hematite colloid aggregation: Implications to iron depletion in estuaries, Langmuir, 20 (2004) 9000-9006.

[24] A.J. Pelley, N. Tufenkji, Effect of particle size and natural organic matter on the migration of nano-and microscale latex particles in saturated porous media, J. Colloid Interface Sci., 321 (2008) 74-83.

[25] R.L. Johnson, G.O. Johnson, J.T. Nurmi, P.G. Tratnyek, Natural organic matter enhanced mobility of nano zerovalent iron, Environ. Sci. Technol., 43 (2009) 5455-5460.

[26] H. Dong, I.M. Lo, Influence of humic acid on the colloidal stability of surface-modified nano zero-valent iron, Water Res., 47 (2013) 419-427.

[27] H.J. Kim, T. Phenrat, R.D. Tilton, G.V. Lowry, Effect of kaolinite, silica fines and pH on transport of polymer-modified zero valent iron nano-particles in heterogeneous porous media, J. Colloid Interface Sci., 370 (2012) 1-10.

[28] J.N. Ryan, M. Elimelech, A. Rebecca, R.W. Harvey, P.R. Johnson, Bacteriophage PRD1 and silica colloid transport and recovery in an iron oxide-coated sand aquifer, Environ. Sci. Technol., 33 (1999) 63-73.

[29] R.A. Abudalo, Y.G. Bogatsu, J.N. Ryan, R.W. Harvey, D.W. Metge, M. Elimelech, Effect of ferric oxyhydroxide grain coatings on the transport of bacteriophage PRD1 and Cryptosporidium parvum oocysts in saturated porous media, Environ. Sci. Technol., 39 (2005) 6412-6419.

[30] S.B. Kim, S.J. Park, C.G. Lee, H.C. Kim, Transport and retention of Escherichia coli in a mixture of quartz, Al-coated and Fe-coated sands, Hydrol. Process., 22 (2008) 3856-3863. 
[31] Y. Liu, C. Zhang, D. Hu, M.S. Kuhlenschmidt, T.B. Kuhlenschmidt, S.E. Mylon, R. Kong, R. Bhargava, T.H. Nguyen, Role of collector alternating charged patches on transport of cryptosporidium parvum oocysts in a patchwise charged heterogeneous micromodel, Environ. Sci. Technol., 47 (2013) 2670-2678.

[32] P. Han, X. Wang, L. Cai, M. Tong, H. Kim, Transport and retention behaviors of titanium dioxide nanoparticles in iron oxide-coated quartz sand: effects of $\mathrm{pH}$, ionic strength, and humic acid, Colloids and Surfaces A: Physicochemical and Engineering Aspects, 454 (2014) 119-127. [33] J. Zhuang, Y. Jin, Interactions between viruses and goethite during saturated flow: Effects of solution pH, carbonate, and phosphate, J. Contam. Hydrol., 98 (2008) 15-21. [34] D. Wang, S.A. Bradford, R.W. Harvey, B. Gao, L. Cang, D. Zhou, Humic acid facilitates the transport of ARS-labeled hydroxyapatite nanoparticles in iron oxyhydroxide-coated sand, Environ. Sci. Technol., 46 (2012) 2738-2745.

[35] P. Jiemvarangkul, W. Zhang, H. Lien, Enhanced transport of polyelectrolyte stabilized nanoscale zero-valent iron (nZVI) in porous media, Chemical Engineering Journal, 170 (2011) $482-491$.

[36] Y. Su, Y.S. Zhao, L.L. Li, C.Y. Qin, F. Wu, N.N. Geng, J.S. Lei, Transport characteristics of nanoscale zero-valent iron carried by three different "vehicles" in porous media, Journal of Environmental Science and Health, Part A, 49 (2014) 1639-1652.

[37] M. Zhang, F. He, D.Y. Zhao, X.D. Hao, Degradation of soil-sorbed trichloroethylene by stabilized zero valent iron nanoparticles: Effects of sorption, surfactants, and natural organic matter, Water Res., 45 (2011) 2401-2414.

[38] R.P. Bailey, T. Bennett, M.M. Benjamin, Sorption onto and recovery of Cr (VI) using ironoxide-coated sand, Water Sci. Technol., 26 (1992) 1239-1244. 
[39] Y. Xu, L. Axe, Synthesis and characterization of iron oxide-coated silica and its effect on metal adsorption, J. Colloid Interface Sci., 282 (2005) 11-19.

[40] W.H. Kuan, S.L. Lo, M.K. Wang, C.F. Lin, Removal of Se(IV) and Se(VI) from water by aluminum-oxide-coated sand, Water Res., 32 (1998) 915-923.

[41] Y. Wang, Y. Li, J.D. Fortner, J.B. Hughes, L.M. Abriola, K.D. Pennell, Transport and retention of nanoscale C60 aggregates in water-saturated porous media, Environ. Sci. Technol., 42 (2008) 3588-3594.

[42] S.A. Bradford, M. Bettahar, J. Simunek, M.T. van Genuchten, Straining and attachment of colloids in physically heterogeneous porous media, Vadose Zone J., 3 (2004) 384-394.

[43] S.A. Bradford, H.N. Kim, B.Z. Haznedaroglu, S. Torkzaban, S.L. Walker, Coupled factors influencing concentration-dependent colloid transport and retention in saturated porous media, Environ. Sci. Technol., 43 (2009) 6996-7002.

[44] R.J. Atkinson, A.M. Posner, J.P. Quirk, Adsorption of potential-determining ions at the ferric oxide-aqueous electrolyte interface, The Journal of Physical Chemistry, 71 (1967) 550558.

[45] M. Bueno, A. Astruc, M. Astruc, P. Behra, Dynamic sorptive behavior of tributyltin on quartz sand at low concentration levels: Effect of $\mathrm{pH}$, flow rate, and monovalent cations, Environ. Sci. Technol., 32 (1998) 3919-3925.

[46] S.H. Joo, S.R. Al-Abed, T. Luxton, Influence of carboxymethyl cellulose for the transport of titanium dioxide nanoparticles in clean silica and mineral-coated sands, Environ. Sci. Technol., 43 (2009) 4954-4959. 
[47] C.H. Ko, M. Elimelech, The "shadow effect" in colloid transport and deposition dynamics in granular porous media: measurements and mechanisms, Environ. Sci. Technol., 34 (2000) $3681-3689$.

[48] Y. Tan, J. Gannon, P. Baveye, M. Alexander, Transport of bacteria in an aquifer sand: experiments and model simulations, Water Resour. Res., 30 (1994) 3243-3252.

[49] S.A. Bradford, M. Bettahar, Concentration dependent transport of colloids in saturated porous media, J. Contam. Hydrol., 82 (2006) 99-117.

[50] T.A. Camesano, K.M. Unice, B.E. Logan, Blocking and ripening of colloids in porous media and their implications for bacterial transport, Colloids and Surfaces A: Physicochemical and Engineering Aspects, 160 (1999) 291-308.

[51] S. Comba, R. Sethi, Stabilization of highly concentrated suspensions of iron nanoparticles using shear-thinning gels of xanthan gum, Water Res., 43 (2009) 3717-3726.

[52] T. Phenrat, H.J. Kim, F. Fagerlund, T. Illangasekare, R.D. Tilton, G.V. Lowry, Particle size distribution, concentration, and magnetic attraction affect transport of polymer-modified $\mathrm{Fe}^{0}$ nanoparticles in sand columns, Environ. Sci. Technol., 43 (2009) 5079-5085.

[53] T. Raychoudhury, N. Tufenkji, S. Ghoshal, Aggregation and deposition kinetics of carboxymethyl cellulose-modified zero-valent iron nanoparticles in porous media, Water Res., 46 (2012) 1735-1744.

[54] R. Konradi, J. Ruhe, Interaction of poly(methacrylic acid) brushes with metal ions: Swelling properties, Macromolecules, 38 (2005) 4345-4354.

[55] X.H. Feng, R. Pelton, Carboxymethyl cellulose: Polyvinylamine complex hydrogel swelling, Macromolecules, 40 (2007) 1624-1630. 
[56] J.K. Jiang, G. Oberdorster, P. Biswas, Characterization of size, surface charge, and agglomeration state of nanoparticle dispersions for toxicological studies, Journal of Nanoparticle Research, 11 (2009) 77-89.

[57] K.M. Sirk, N.B. Saleh, T. Phenrat, H.J. Kim, B. Dufour, J. Ok, P.L. Golas, K. Matyjaszewski, G.V. Lowry, R.D. Tilton, Effect of adsorbed polyelectrolytes on nanoscale zero valent iron particle attachment to soil surface models, Environ. Sci. Technol., 43 (2009) 38033808.

[58] J. Fatisson, S. Ghoshal, N. Tufenkji, Deposition of carboxymethylcellulose-coated zerovalent iron nanoparticles onto silica: Roles of solution chemistry and organic molecules, Langmuir, 26 (2010) 12832-12840.

[59] R. Kretzschmar, H. Sticher, Transport of humic-coated iron oxide colloids in a sandy soil: Influence of $\mathrm{Ca}^{2+}$ and trace metals, Environ. Sci. Technol., 31 (1997) 3497-3504.

[60] R.F. Domingos, N. Tufenkji, K.J. Wilkinson, Aggregation of titanium dioxide nanoparticles: role of a fulvic acid, Environ. Sci. Technol., 43 (2009) 1282-1286. [61] C.J. Davis, E. Eschenazi, K.D. Papadopoulos, Combined effects of $\mathrm{Ca}^{2+}$ and humic acid on colloid transport through porous media, Colloid \& Polymer Science, 280 (2002) 52-58.

[62] J.A. Redman, S.L. Walker, M. Elimelech, Bacterial adhesion and transport in porous media: role of the secondary energy minimum, Environ. Sci. Technol., 38 (2004) 1777-1785.

[63] N. Tufenkji, M. Elimelech, Deviation from the classical colloid filtration theory in the presence of repulsive DLVO interactions, Langmuir, 20 (2004) 10818-10828.

[64] H.N. Kim, S.L. Walker, S.A. Bradford, Coupled factors influencing the transport and retention of Cryptosporidium parvum oocysts in saturated porous media, Water Res., 44 (2010) $1213-1223$. 
[65] M.W. Hahn, C.R. O'Melia, Deposition and reentrainment of brownian particles in porous media under unfavorable chemical conditions: Some concepts and applications, Environ. Sci. Technol., 38 (2004) 210-220.

[66] C.Y. Shen, B.G. Li, Y.F. Huang, Y. Jin, Kinetics of coupled primary- and secondaryminimum deposition of colloids under unfavorable chemical conditions, Environ. Sci. Technol., 41 (2007) 6976-6982.

[67] M. Tong, T.A. Camesano, W.P. Johnson, Spatial variation in deposition rate coefficients of an adhesion-deficient bacterial strain in quartz sand, Environ. Sci. Technol., 39 (2005) 36793687.

[68] F. He, D.Y. Zhao, C. Paul, Field assessment of carboxymethyl cellulose stabilized iron nanoparticles for in situ destruction of chlorinated solvents in source zones, Water Research 44 (2010) 2360-2370. 
Table 1. Parameters on CMC-ZVI sorption and transport with various porous media.

\begin{tabular}{|c|c|c|c|c|c|c|c|}
\hline $\begin{array}{c}\text { Collector } \\
\text { grains }\end{array}$ & $\begin{array}{c}\text { Laximum capacity } \\
\text { Q, mg g }\end{array}$ & $\begin{array}{c}\text { Langmuir } \\
\text { affinity constant } \\
\mathrm{b}, \mathrm{L} \mathrm{mg}^{-1}\end{array}$ & $\begin{array}{c}\text { Adsorption } \\
\text { coefficient } \\
\mathrm{k}_{\mathrm{ads}}, \mathrm{s}^{-1}\end{array}$ & $\begin{array}{c}\text { Pore } \\
\text { velocity, } \\
\mathrm{cm} \mathrm{s}^{-1}\end{array}$ & $\begin{array}{c}\text { hydrodynamic } \\
\text { dispersion } \\
\text { coefficient, } \mathrm{cm}^{2} \mathrm{~s}^{-1}\end{array}$ & $\begin{array}{c}\text { Equilibrium } \\
\text { adsorption uptake } \\
\mathrm{S}_{\mathrm{max}}, \mathrm{mg} \mathrm{g}^{-1}\end{array}$ & $\begin{array}{c}\text { Filtration } \\
\text { coefficient, } \\
\mathrm{k}_{\mathrm{fil}}, \mathrm{s}^{-1}\end{array}$ \\
\hline $\begin{array}{c}\text { Plain } \\
\text { Sand }\end{array}$ & 0.1466 & 22.4 & $2.67 \times 10^{-6}$ & 0.0353 & 0.0061 & 0.117 & $2.15 \times 10^{-4}$ \\
\hline IOCS & 1.999 & 3.74 & $4.67 \times 10^{-6}$ & $0.0706^{*}$ & 0.0122 & 0.120 & $5.63 \times 10^{-5}$ \\
\hline AOCS & 0.6345 & 34.9 & $4.28 \times 10^{-6}$ & 0.0353 & 0.0061 & 0.724 & $4.72 \times 10^{-4}$ \\
\hline
\end{tabular}

* Transport data taken from He et al. (2009) under the same experimental conditions. 


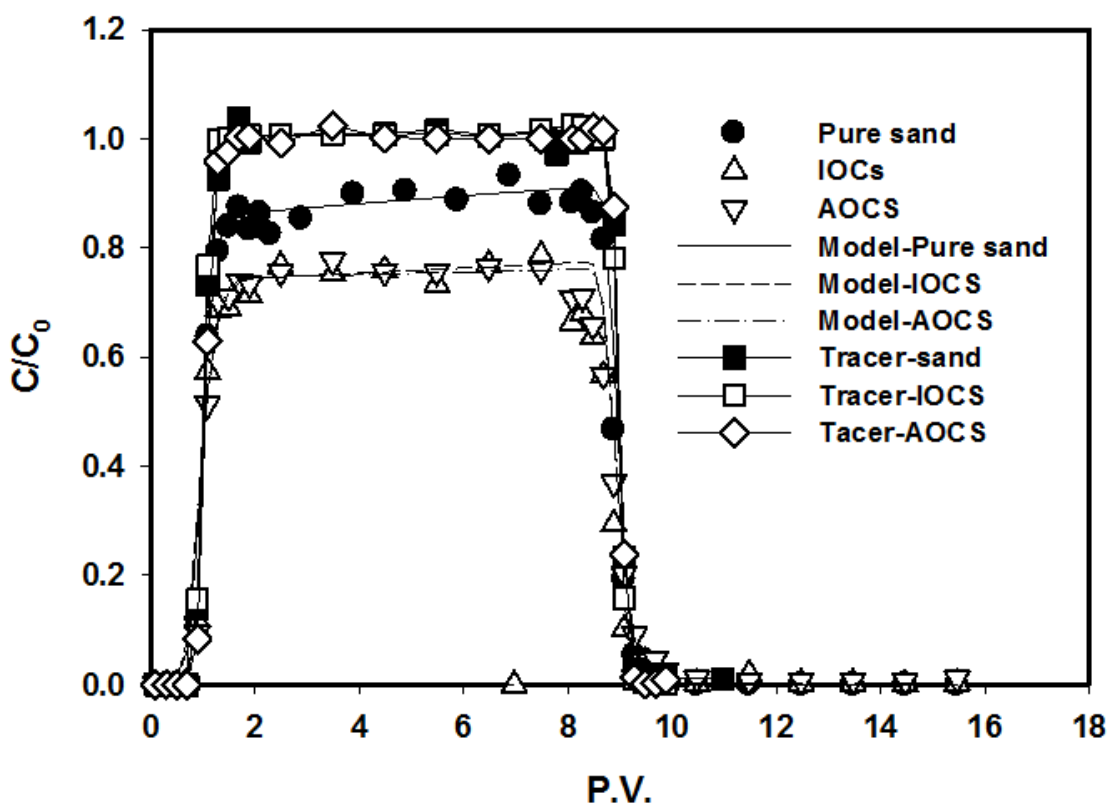

Figure 1. Breakthrough curves of CMC-stabilized ZVI nanoparticles through plain sand, IOCS and AOCS columns. Data plotted as mean of duplicates. Influent ZVI concentration was $0.2 \mathrm{~g} \mathrm{~L}^{-}$ ${ }^{1}$. Pore velocity was $0.0353 \mathrm{~cm} \mathrm{~s}^{-1}$. 


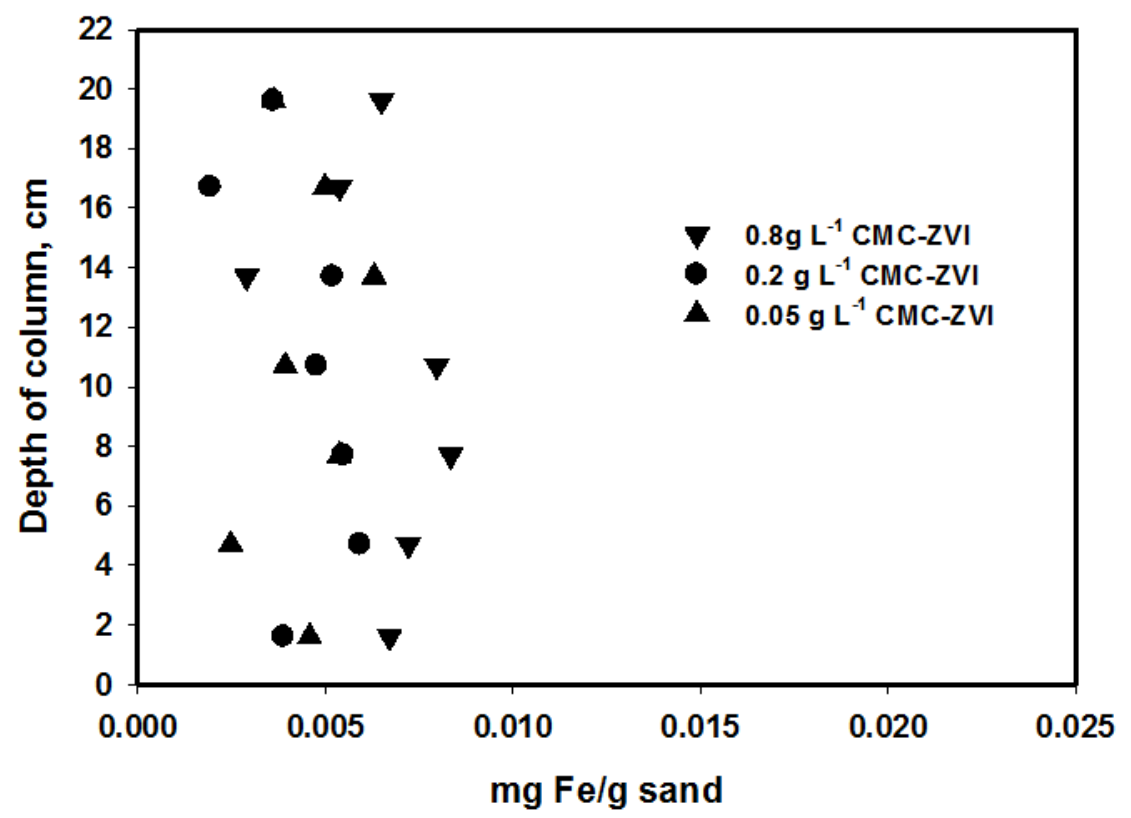

Figure 2. Representative retention profiles for CMC-stabilized ZVI in plain sand column following saturation/breakthrough and subsequent elution runs. The influent concentration was $0.05,0.2$ or $0.8 \mathrm{~g} / \mathrm{L}^{-1}$. 


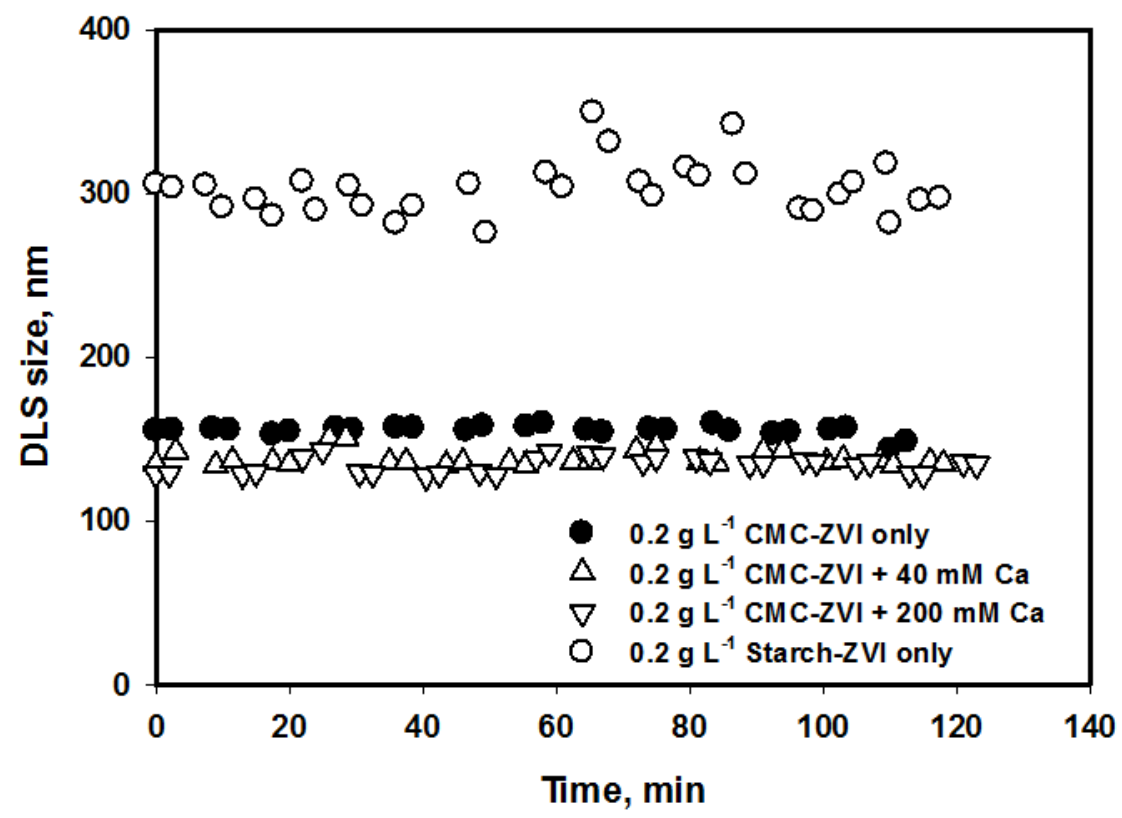

Figure 3. DLS-based hydrodynamic size of CMC- or starch-stabilized ZVI nanoparticles as a function of time. 

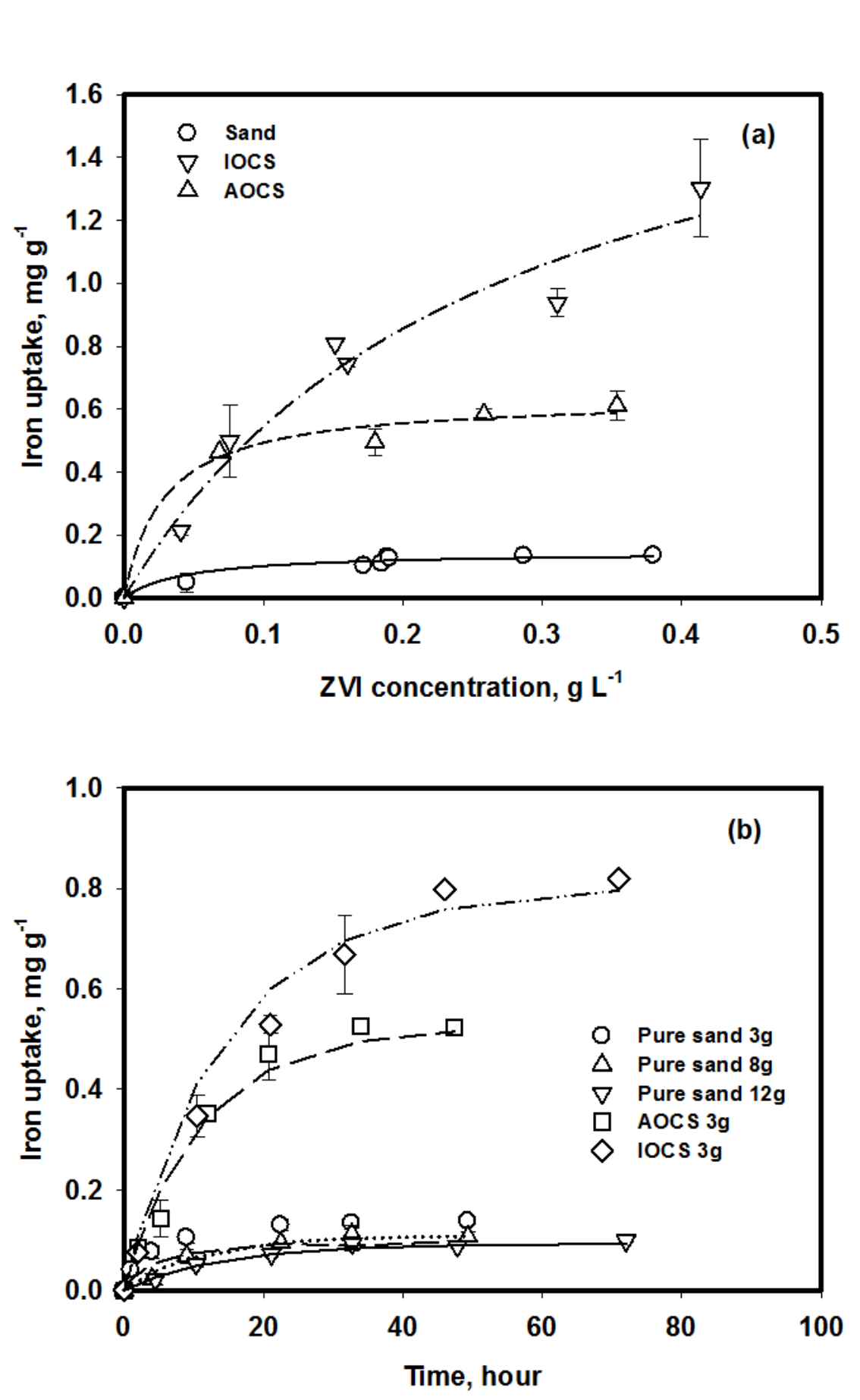

Figure 4. Adsorption isotherms (a) and kinetics (b) of CMC-stabilized ZVI nanoparticles on plain sand, IOCS and AOCS. Data plotted as mean of duplicates. 


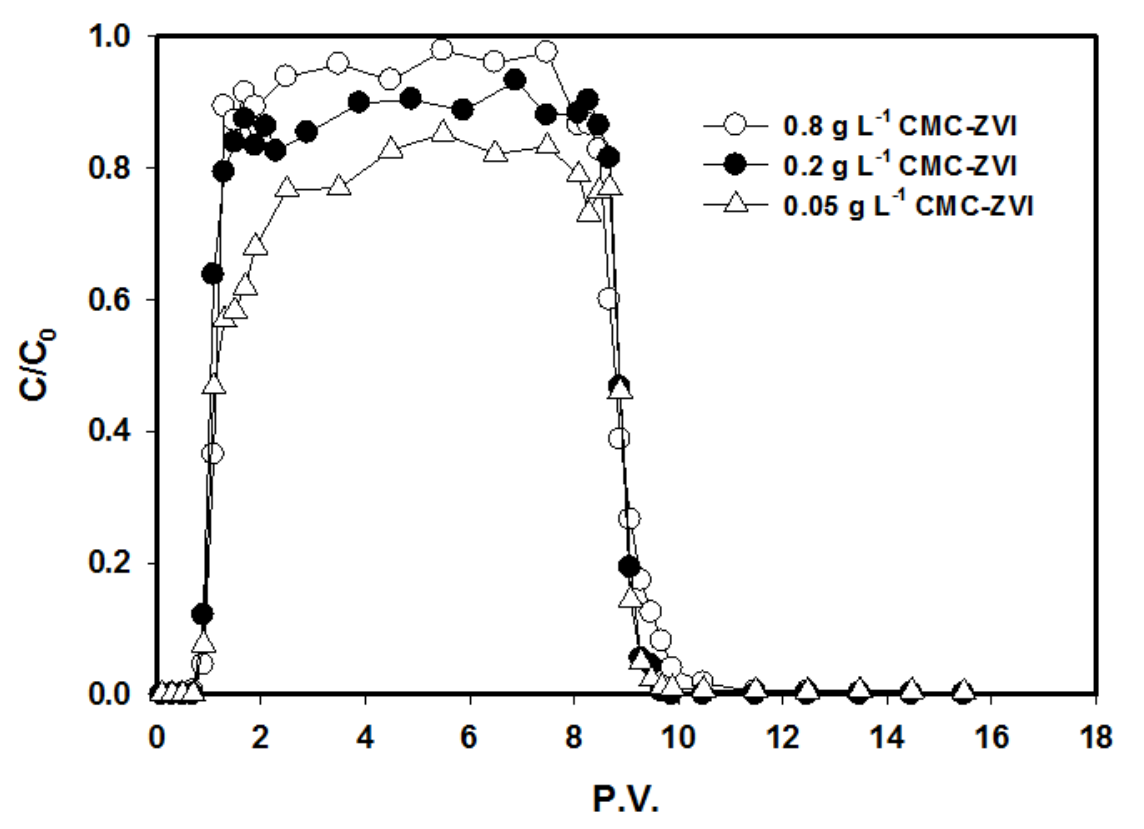

Figure 5. Breakthrough curves of CMC-stabilized ZVI nanoparticles in response to various influent ZVI concentrations through sand columns. Data plotted as mean of duplicates. Pore velocity was $0.0353 \mathrm{~cm} \mathrm{~s}^{-1}$. 


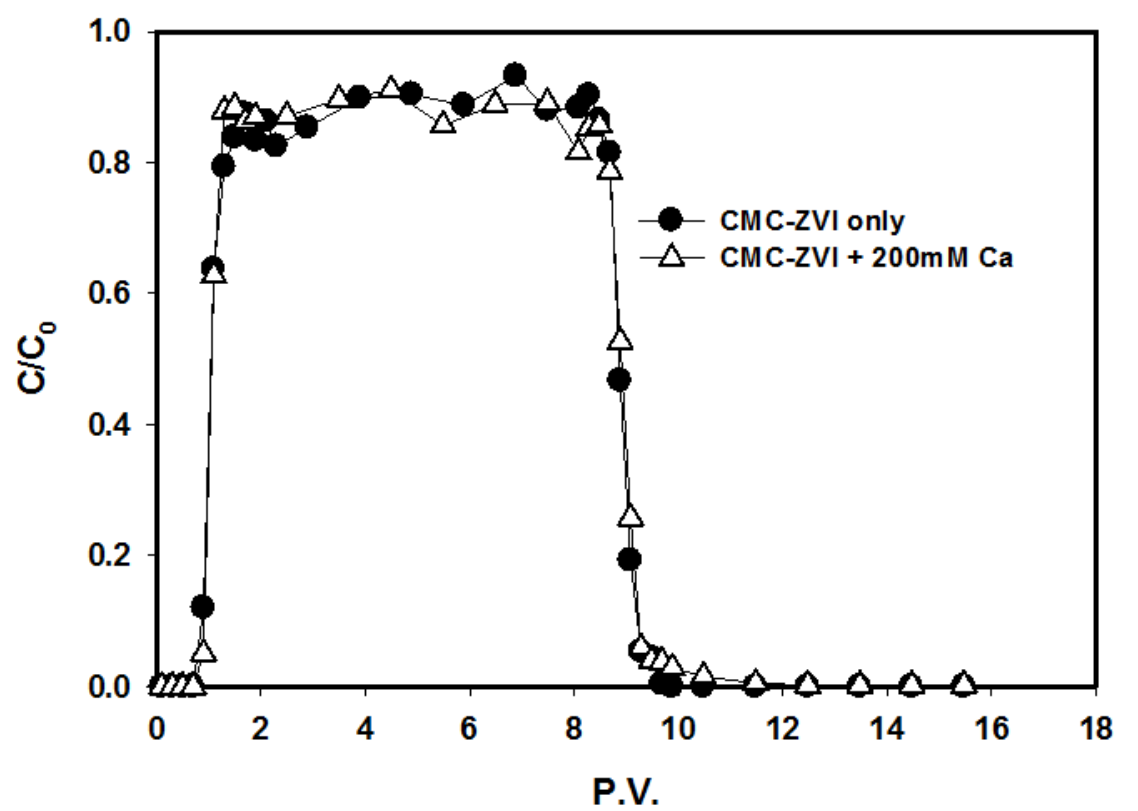

Figure 6. Breakthrough curves of CMC-stabilized ZVI nanoparticles through sand columns with or without $200 \mathrm{mM} \mathrm{CaCl}_{2}$. Data plotted as mean of duplicates. Influent ZVI concentration was $0.2 \mathrm{~g} \mathrm{~L}^{-1}$. Pore velocity was $0.0353 \mathrm{~cm} \mathrm{~s}^{-1}$. 


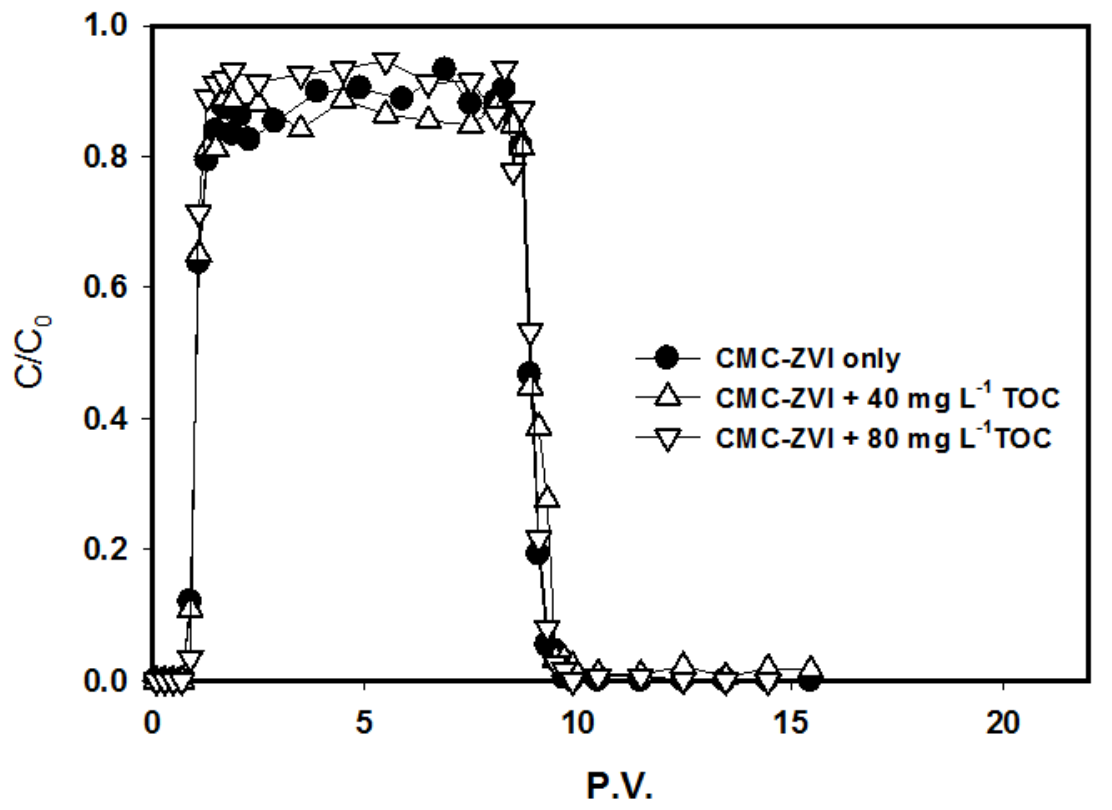

Figure 7. Breakthrough curves of CMC-stabilized ZVI nanoparticles thorough sand columns in the presence of various concentrations of natural organic matter. Data plotted as mean of duplicates. Influent ZVI concentration was $0.2 \mathrm{~g} \mathrm{~L}^{-1}$. Pore velocity was $0.0353 \mathrm{~cm} \mathrm{~s}^{-1}$. 


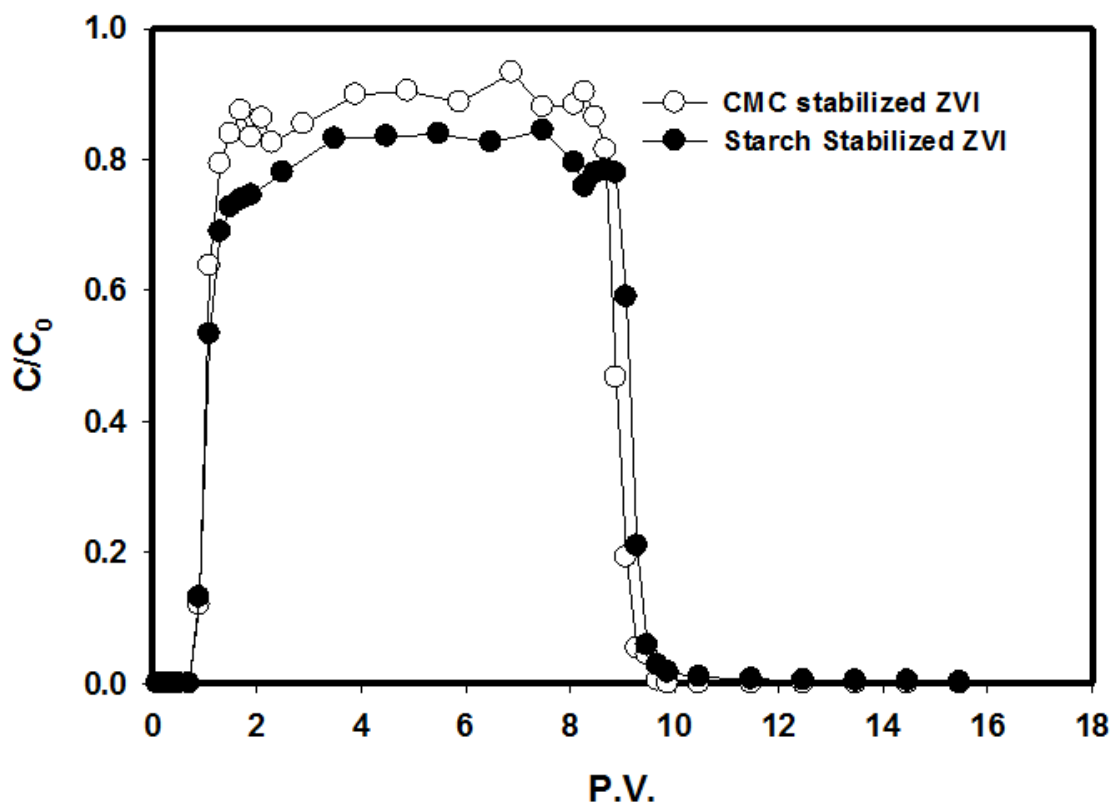

Figure 8. Representative breakthrough curves of CMC- or starch-stabilized ZVI nanoparticles through plain sand columns. Data plotted as mean of duplicates. Influent ZVI concentration was $0.2 \mathrm{~g} \mathrm{~L}^{-1}$. Pore velocity was $0.0353 \mathrm{~cm} \mathrm{~s}^{-1}$. 